\title{
La historia pendiente: exiliadas argentinas de los setenta. Una aproximación a través de las cartas*
}

\section{Unsettled History: Argentine Exiled Women of the Seventies. An Approach through Letters}

\author{
Bárbara Ortuño Martínez. \\ ORCID iD: https://orcid.org/0000-0003-3864-9086 \\ Universidad de Alicante
}

\begin{abstract}
Este trabajo es un acercamiento al exilio argentino de los años setenta, en particular el que tuvo como destino España, desde la historia de las mujeres. A lo largo de las siguientes líneas incidiremos, por un lado, en el vacío historiográfico referido a las exiliadas, quienes compusieron la mitad de esta migración forzada tras la implantación de la última dictadura cívico-militar (1976-1983). Y, por otro, analizaremos el fondo «Cartas de la Dictadura» para ahondar en las virtudes y defectos de los epistolarios albergados, deteniéndonos en sus posibilidades para el estudio de lo público y lo privado con una perspectiva de género.

Palabras clave: Exilio; Argentina; Cartas; Género; Público-Privado.

This work is an approach to Argentine exile in the Seventies, in particular, which has as destination Spain, from the point of view of Women History. On the one hand, we will fill the historiographical void related to the exiled women, which have meant the half of the forced migration that took place in the last civic-military dictatorship (1976-1983). On the other hand, we will analyse the collection «Cartas de la Dictadura» to go deeper into the virtues and defects of letters as a historical source, highlighting their possibilities for the study of the public and the private with a gender perspective.
\end{abstract}

Keywords: Exile; Argentine; Letters; Gender; Public-Private.

Copyright: (C) 2020 CSIC. Este es un artículo de acceso abierto distribuido bajo los términos de la licencia de uso y distribución Creative Commons Reconocimiento 4.0 Internacional (CC BY 4.0).

* Este trabajo se ha realizado en el marco del proyecto «Género, compromiso y transgresión en España, 1890-2016» (FEM2016-76675-P), financiado por el Ministerio de Economía y Competitividad, y radicado en el Instituto Universitario de Investigación de Estudios de Género (IUIEG) de la Universidad de Alicante. Sus primeras versiones fueron discutidas en el LVI Congreso Internacional de Americanistas (Salamanca, 2018) y en la Jornada de Estudios «Subjetividades, transgresión y género. Cuestiones metodológicas» (París, 2019). En ambos casos, agradecemos los agudos comentarios de nuestras colegas, que sin duda han posibilitado su concreción. 


\section{Introducción}

Nuestra investigación surge de una pregunta concreta: ¿Por qué, si tanto se ha avanzado en el campo de estudio de los exilios, la participación de las mujeres y los análisis de género continúan siendo una cuestión pendiente en diversas historiografías iberoamericanas? En 2005, una de las principales especialistas en el exilio argentino de los años setenta que tuvo como destino la península ibérica, concretamente Cataluña, partía de una duda similar, retomando la reflexión de Montserrat Roig —enunciada en 1980_ sobre la ausencia de las republicanas en los estudios referidos al exilio y la Guerra Civil española. La conclusión de Silvina Jensen era similar a la que había llegado Roig veinticinco años atrás: las mujeres ocupaban un lugar anecdótico y desigual en las memorias referidas al exilio argentino de los años setenta. Es más, por aquel entonces, incidía en la idea de una «doble subrepresentación»: Por un lado, la de la expatriación en sí en las memorias de la dictadura y, por otro, la de las mujeres en las narrativas públicas y en los relatos históricos sobre el exilio. ${ }^{1}$

En el caso de la historiografía española, desde los años noventa del siglo pasado, se multiplicaron los resultados que esclarecían el papel protagonista de las exiliadas republicanas, con sus múltiples aristas, sobre todo en los destinos mexicano y francés, pero también en otros menos conocidos como el argentino o el norteafricano. ${ }^{2}$ Sin embargo, todavía hoy existe cierta reticencia a incorporar dichas aportaciones en la historiografía del exilio y persiste la diferencia entre un exilio oficial (masculino) y otro extraoficial y/o de acompañamiento (femenino). ${ }^{3}$ Por el lado argentino, el campo de estudio referido al exilio ha sufrido un avance sobresaliente en la última década, que coincide con el interés público sobre la última dictadura cívicomilitar (1976-1983) y, en general, por los años setenta. En este sentido, según diversas autoras, han sido determinantes factores como el diálogo intergeneracional e interdisciplinario, la interlocución con otras historiografías sobre procesos de violencia política masiva, como el franquismo, la apertura de nuevos archivos, las políticas de «Verdad, Justicia y Memoria» de las administraciones Kirchner, así como la institucionalización de la historia reciente y los estudios de la memoria en toda América Latina. ${ }^{4}$

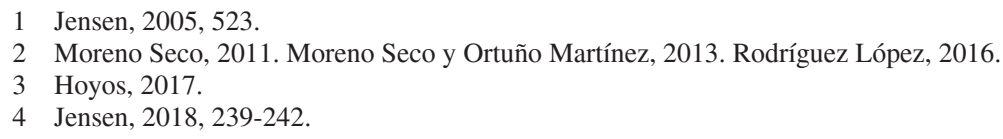


Todo ello ha provocado que se revierta la tendencia historiográfica en un país como Argentina, el cual, a pesar de contar con una vasta tradición y reconocimiento internacional en los estudios migratorios, había otorgado un espacio marginal a las migraciones políticas y de carácter forzado. De este modo, el exilio argentino de los años setenta y, en general, los exilios que asolaron el continente americano desde la década anterior, se comenzaron a abordar progresivamente desde parámetros psicológicos, literarios, jurídicos, diplomáticos, antropológicos e históricos que, en numerosos casos, pusieron el foco en temáticas cada vez más presentes en la historiografía, como son la alteridad o la reconfiguración de identidades.

Sin embargo, ¿dónde están las mujeres cuando hablamos de exilios? Por lo que concierne a Argentina, este vacío continúa siendo abismal, aunque dicha falencia, que parecía dispuesta a perpetuarse, ${ }^{5}$ viene experimentando un giro radical, casi simultáneo a la elaboración del presente trabajo, tal y como a continuación señalaremos. Por diversas fuentes cuantitativas, sabemos que la mitad del exilio argentino de la última dictadura cívicomilitar estuvo constituido por mujeres. En cuanto a cifras totales se refiere, pareciera haberse llegado a un consenso al estimar dicho éxodo en quinientas mil personas, cifra que por su parte lo asemeja también cuantitativamente al exilio republicano español. No obstante, como señaló Guillermo Mira, carecemos de datos concluyentes sobre el número de argentinos/as que se instaló en España durante el período referido. Los datos oscilan entre las doce y quince mil personas, que apunta el Colectivo IOE, ${ }^{6}$ a las cincuenta mil, solo en Madrid, que señalaron los impulsores de la Casa Argentina hacia $1979 .{ }^{7}$ Son precisamente los factores que convirtieron a la península ibérica en uno de los principales destinos del exilio argentino de los años setenta, los mismos que dificultan la posibilidad de obtener una cifra cerrada. Entre ellos destacamos: las entradas como turistas y la posesión de la ciudadanía italiana o española, debido a los flujos migratorios asentados desde la etapa masiva (1890-1930) y reforzados con la llegada del exilio republicano (1936-1975), así como durante la nueva inmigración de posguerra $(1946-1960){ }^{8}$

5 Yankelevich, 2016, 22.

6 Equipo de investigación social, formado por Walter Actis, Miguel Ángel de Prada y Carlos Pereda. Grupo Cooperativo Tangente, Madrid.

7 Mira, 2003, 187-188.

8 Ortuño Martínez, 2018. 
Para el caso español poseemos un retrato del colectivo asentando en Cataluña, donde las cifras oscilan entre tres mil y diez mil personas. A través del censo consular, conocemos que, entre 1973 y 1983, las mujeres representaron el $42 \%$ de la comunidad, sin diferenciar a exiliadas de inmigrantes. ${ }^{9}$ Pero es sobresaliente el dato de que durante el periodo de mayor violencia represiva (1976-1979), la presencia de mujeres aumentó con respecto a etapas anteriores y posteriores. Esta migración forzosa estuvo compuesta en su mayoría por mujeres y hombres procedentes de sectores urbanos, particularmente de las principales ciudades del país - Buenos Aires, La Plata, Rosario, Mar del Plata, Bahía Blanca, Córdoba y Mendo$\mathrm{za}-$, las cuales congregaban a la mayoría del estudiantado universitario y secundario. Cruzando los datos ofrecidos por los registros demográficos españoles — censos de población, padrones municipales, anuarios de trabajadores extranjeros, etc. - y los estudios sobre inmigración latinoamericana en España y en Cataluña, Silvina Jensen indica que, entre 1973 y 1983, las personas de entre veinticinco y cincuenta y nueve años representaron el $70 \%$ del total, seguidas de quienes tenían entre quince y veinticuatro años, que se situaron en un 20,5\%. ${ }^{10}$ Desde nuestro punto de vista, las edades de quienes compusieron la comunidad exiliada en Cataluña, que apuntan un perfil muy similar al del colectivo exiliado en Madrid, son solo una pequeña muestra de la represión sistemática hacia la juventud ejercida por el ejército, la policía y las fuerzas paramilitares. Esto nos lleva a afirmar que la juventud adquirió un papel relevante en este éxodo sin precedentes en la historia de Argentina, acorde con el papel que los y las jóvenes adquirieron en el mundo occidental tras los mayos del sesenta y ocho ${ }^{11}$ y en consonancia con las particularidades del contexto regional.

De forma muy esquemática, señalamos que en 1973 el candidato peronista Héctor José Cámpora asumió el poder arropado por aquella «juventud maravillosa» y, tras unos meses de gobierno, convocó unas nuevas elecciones sin restricciones para Juan Domingo Perón, proscrito desde 1955. La muerte del líder del peronismo en 1974 provocó que María Estela Martínez, esposa de Perón y representante de la extrema derecha del movimiento, asumiera el poder de un país que fue incapaz de gobernar. La conflictividad política y social, que tuvo como resultado una escalada de violencia, sumada a la crisis económica, ofreció el escenario perfecto para un nuevo golpe

9 Jensen, 2005, 532.

10 Idem.

11 Manzano, 2017 
militar, autodenominado «Proceso de reorganización nacional», que se prolongaría durante siete años. ${ }^{12}$ En este contexto, la juventud, acusada de estar embebida del «veneno subversivo», como rezaba la prensa del momento, se convirtió en el principal enemigo de las autoridades gobernantes. ${ }^{13}$ Dentro de este sector poblacional, fueron las mujeres militantes quienes sufrieron una doble represión por haber trasgredido, además, los valores supuestamente femeninos, alejándose de su «deber natural» de dedicarse en exclusiva al espacio doméstico y familiar; ${ }^{14}$ habiendo dado, por tanto, un salto abrupto de lo privado a lo público, espacio por excelencia de los varones, según la asignación de géneros de la cultura heteropatriarcal.

Sin embargo, tenemos poca información de las mujeres exiliadas, carecemos de un perfil socioeconómico detallado y tan solo contamos con retazos de sus experiencias, centradas fundamentalmente en los motivos de salida, disgregados en las primeras obras testimoniales, en un claro desequilibrio y con tendencia a visibilizar — en exclusiva - a determinadas personalidades del mundo cultural. ${ }^{15}$ En el caso de la península ibérica, referidos únicamente a la experiencia exiliar, además del trabajo de Jensen sobre Cataluña, contamos con los testimonios recopilados por la antropóloga Margarita del Olmo, pionera en la investigación sobre el exilio argentino de los años setenta en España, ${ }^{16}$ además de, por otro lado, los resultados que sustentan la presente investigación, basados en fuentes orales primordialmente, que en breve verán la luz.

Dentro de las Ciencias Sociales, han sido la Psicología, el Psicoanálisis y la Salud Mental las únicas disciplinas que han indagado en algunas cuestiones de género como las referidas al impacto del exilio y el retorno en las parejas y los/as hijos/as, o la redefinición de los roles o papeles tradicionales asociados a «lo masculino» y «lo femenino» ${ }^{17}$ Los motivos de este retraso en la indagación histórica los desconocemos y creemos que en los próximos años este panorama habrá sufrido modificaciones. Algunos trabajos, además de los ya señalados, comienzan a transitar una senda esperanzadora, entre ellos destacamos el monográfico de la revista de análisis

12 Franco, 2012.

13 «Carta abierta a los padres argentinos», Revista Gente, Buenos Aires, 16 de diciembre de 1976. Disponible en: https://www.educ.ar/recursos/128857/carta-abierta-a-padres-argentinos-enrevista-gente-1976 [Consultado: 21/11/2019].

14 Antonio, 2008. Lewin y Wornat, 2013.

15 Jensen, 2005, 529.

16 Olmo, 1989; 2002.

17 Gringberg y Gringberg, 1984. Vásquez y Araujo, 1990. 
cultural Kamtchatka, coordinado por Paula Simón en 2016. El mismo, si bien no se aleja de los testimonios de las mujeres que compusieron la elite literaria del exilio argentino de los años setenta,${ }^{18}$ abre un abanico de posibilidades al presentar análisis comparados entre los exilios europeos y latinoamericanos de los siglos XX y XXI, al ahondar en el mundo de las representaciones y las configuraciones identitarias, así como al poner en primera línea algunos de los temas que están reclamando un lugar visible en la agenda investigadora. Entre ellos, destacamos la relación entre maternidades y expatriaciones e infancias y exilios, la influencia de las experiencias exiliares en el desarrollo de los feminismos latinoamericanos o el exilio entendido como una de las aristas del compromiso político y, sobre todo, como consecuencia de la violencia militar y dictatorial, teniendo presentes los resultados diferenciados por cuestiones de género. ${ }^{19}$

Por nuestra parte, el acercamiento al exilio argentino de los años setenta desde la óptica de la historia de las mujeres y con una perspectiva de género proviene de dos líneas de estudio paralelas que tienden a cruzarse en un mismo punto. Por un lado, comenzamos perfilando las características de la segunda generación del exilio republicano español en Argentina y analizando el compromiso político que asumieron fundamentalmente las mujeres que conformaron el sector más joven de esta comunidad. ${ }^{20} \mathrm{Te}-$ niendo en cuenta la intersección del género, la edad, la clase, la etnia y las propias tipologías migratorias, comenzamos a trazar las experiencias e historias de vida de quienes construyeron su identidad como un proceso de significación de las culturas políticas de izquierda, aplicando una metodología inductiva que, en términos de Ana Amado, nos permitió afrontar la interrogación genealógica sobre la captura de subjetividades por la entidad familiar y sus consecuencias políticas. ${ }^{21}$ Contamos con escasos estudios y datos concretos que hablen de cuántos de los y las descendientes de quienes se exiliaron o emigraron durante la Guerra Civil y la posguerra a Argentina militaron en organizaciones de la nueva izquierda, o cuántas personas sufrieron la cárcel, la muerte o el exilio, pero, tal y como señalaron Rey y Coraza, el hecho de que sea frecuente hallar casos de estas características nos lleva a la necesidad de plantear esta cuestión y avanzar en su reflexión. ${ }^{22}$

18 Simón, 2016. Davidovich, 2016.

19 Álvarez, 2019, 427-447. González de Olega et al., 2019. Burgos Fonseca, 2018. Saidón, 2019. Ortuño Martínez, 2019, 25-40.

20 Ortuño Martínez, 2015.

21 Amado, 2003, 55.

22 Rey y Coraza, 2009,138. 
Por otro lado, volvimos a «encontrarnos» con las exiliadas argentinas de la última dictadura cívico-militar a través de un estudio realizado junto con Mónica Moreno sobre la juventud revolucionaria en la España de los años setenta. ${ }^{23}$ Como es sabido, los años sesenta y setenta se caracterizaron por ser una etapa histórica de profundas transformaciones en el espacio social y político, pero también en la vida privada. En Estados Unidos, en Europa, en los países asiáticos y de América Latina existió la convicción de que «otro mundo era posible»; en palabras de un exiliado argentino en España: «nuestra generación se planteó alcanzar la luna [...] y además le pareció que medio podía llegar». ${ }^{24}$ Centramos nuestras pesquisas en la transgresión manifestada por mujeres y hombres en términos políticos y personales siguiendo tres ejes: las ideas, las acciones y los comportamientos cotidianos, ahondando en las contradicciones y reconfiguraciones identitarias que surgieron cuando el compromiso y la transgresión cuestionaron las relaciones familiares y de género de la época, difuminando las fronteras entre lo público y lo privado. Para ello, pusimos el foco en la juventud militante de la extrema izquierda española y argentina y, en el caso de esta última, interesándonos por la vía del exilio, ya que, además de no estar explorada en los términos expuestos, sumaba nuevas situaciones a la vida cotidiana y diferentes contradicciones a una subjetividad militante que transitó múltiples derroteros.

Desde entonces, el objetivo principal de nuestra investigación reside, por un lado, en dar visibilidad a quienes compusieron la mitad de la diáspora en términos cuantitativos, es decir, las mujeres. Y, por otro, en ahondar en las vivencias de la vida cotidiana en el exterior, en la afectividad, en el conjunto de sentimientos y emociones que mujeres y hombres experimentaron en el transcurso de sus días en el exterior, teniendo en cuenta las contradicciones que generaron las diferencias de género y el compromiso militante. En concreto, abordamos las experiencias públicas y privadas de quienes durante su adolescencia y juventud militaron en organizaciones de izquierda revolucionaria como el Partido Revolucionario de los Trabajadores-Ejército Revolucionario del Pueblo (PRT-ERP), Montoneros y organizaciones de base de la «tendencia revolucionaria» del peronismo, las cuales se diferenciaron de las agrupaciones y partidos vinculados con la izquierda histórica por el destacado número de mujeres que compusieron su militancia. ${ }^{25} \mathrm{Y}$ en

23 Ortuño Martínez y Moreno Seco [en prensa].

24 Olmo, 2002, 254.

25 Marta, 1996, 376. Pozzi, 2001, 239. 
este caso, para avanzar en el establecimiento de estos vínculos entre lo personal y lo político, lo público y lo privado, decidimos privilegiar una fuente excepcional en la «escritura del yo» como es la correspondencia personal.

\section{Las cartas exiliadas. Virtudes y defectos de una fuente singular}

Centramos nuestra investigación en el fondo «Cartas de la Dictadura», albergado en la Biblioteca Nacional de Argentina Mariano Moreno, en Buenos Aires, concretamente en las cartas personales producidas y recibidas desde el exilio, en particular del que se asentó en España, pero también en otros destinos como Francia, Suecia, Israel e Italia. Dicho acervo documental se puso en marcha en octubre de 2012 con el objetivo de recopilar correspondencia personal enmarcada, centralmente, en los años de la última dictadura cívico-militar argentina. Las cartas custodiadas abordan temas vinculados a la militancia política, el exilio, las experiencias carcelarias, la guerra de Malvinas y, en general, la vida cotidiana durante el período referido. En la actualidad esta colección, compuesta por más de setecientas epístolas, se encuentra abierta a la recepción de nuevos materiales. Además, existe una muestra itinerante con el objetivo de «crear conciencia sobre la importancia de preservar aquellas cartas que permanecen desperdigadas, pero que tomadas en conjunto escriben las páginas de nuestra historia reciente». ${ }^{26}$

De ahí que nos genere inquietud el hecho de que un acervo documental de tanta potencialidad hermenéutica todavía no haya sido abordado de forma sistemática para analizar diferentes aristas pendientes de estudio. ${ }^{27}$ Es cierto que en los últimos años se ha publicado alguna obra académica tomando como base epistolarios producidos desde el exterior, así como recopilaciones de cartas en la prensa escrita. En concreto, nos estamos refiriendo a la obra basada en la correspondencia inédita de Juan Domingo Perón durante sus dieciocho años de exilio (1955-1973), con especial incidencia

26 Biblioteca Nacional de Argentina Mariano Moreno, «Cartas de la Dictadura. Muestra Itinerante», Buenos Aires, marzo-abril de 2018. Disponible en: https://www.bn.gov.ar/agenda-cultural/ cartas-de-la-dictadura-1 [Consultado: 16/07/2019].

27 Por nuestra parte, acotamos la investigación a los fondos Cristina Zuker; Laura Guissani; Virginia Giussani; Graciela Golkchluk y Hector Haboba; Juan José Salinas; Diana Cruces y Omar David Varela. Biblioteca Nacional de Argentina Mariano Moreno, Buenos Aires (BNA), Departamento de Archivos, Cartas de la Dictadura, Correspondencia. 
de los textos de finales de los años sesenta y principios de los setenta: ${ }^{28}$ así como a las cartas cruzadas entre los escritores Osvaldo Báyer — exiliado en Alemania- y Osvaldo Soriano - exiliado en Bruselas y París-, publicadas por el primero en el diario Página 12 durante el año 2007. ${ }^{29}$ En ambos casos, es evidente que sus protagonistas son figuras masculinas representativas del establishment político y del mundo de las letras.

Hasta donde sabemos, para el caso argentino todavía carecemos de trabajos que aborden los epistolarios producidos por mujeres, en particular desde el exilio. No obstante, contamos con investigaciones referidas a las experiencias carcelarias que nos pueden servir de faro, al mismo tiempo que asientan conceptos y remarcan cuestiones metodológicas de la escritura epistolar con diferentes resultados en cuanto a la aplicación de la perspectiva de género se refiere. ${ }^{30}$ Por el lado español, el tratamiento de la escritura popular y de las cartas en particular, fundamentalmente relacionadas con la Guerra Civil, pero también con las experiencias carcelarias y de campos de concentración durante la dictadura franquista, ha experimentando un salto cualitativo en los últimos años. ${ }^{31} \mathrm{Si}$ centramos el foco en el exilio, más allá de los estudios de caso de los epistolarios de las figuras más representativas de la política y de la alta cultura de la expatriación republicana, en buena parte realizados desde la historia de la literatura y que requerirían un análisis específico, consideramos pertinente destacar obras, como la de Guadalupe Adámez Castro, ${ }^{32}$ por su tratamiento de la fuente, pero también por su aportación a la historia del exilio republicano «desde abajo». Asimismo, entre los aportes historiográficos de la nueva historia cultural, subrayamos el trabajo de Elena Díaz Silva sobre las masculinidades en el exilio republicano en México, en este caso también sustentado en la correspondencia - la del poeta Emilio Prados_- y bien cimentado en la teoría de género y de la historia de las emociones. ${ }^{33}$ Por último, hemos de mencionar la investigación que viene realizando Pilar Domínguez Prats sobre la Transición española desde la perspectiva de género, en particular sobre las mujeres exiliadas en México y la segunda generación, algunos de cuyos resultados, en concreto los derivados del análisis de fuentes epistolares,

28 Chiaramonte y Klein, 2017.

29 Bayer, 2007.

30 Beguán et al., 2006. Jensen y Moreno, 2013. Antonio, 2016; 2019.

31 Sierra Blas, 2016.

32 Adámez Castro, 2017.

33 Díaz Silva, 2019. 
fueron recientemente expuestos en el Encuentro «Epistolarios del extremo. Campos, cárceles y exilios en el siglo XX». ${ }^{34}$

Este somero estado de la cuestión estaría incompleto si no hiciésemos referencia al trabajo de Carolina Rodríguez-López y Daniel Ventura Herranz, «De exilios y emociones». Dicho texto, pionero al aplicar los métodos y conceptos aportados por la historia de las emociones al exilio republicano de la Guerra Civil, fue concebido como «una cartografía emocional» de tres referentes culturales de la expatriación en los Estados Unidos - Américo Castro, Pedro Salinas y Fernando de los Ríos-, y supuso el fruto macerado del estudio sistemático de su intercambio de cartas, epistolarios editados y cartas inéditas localizadas en archivos particulares. Entre todas sus afirmaciones destacamos una en particular, perfectamente aplicable a los epistolarios producidos en contextos de exilio, que incide en el hecho de que la escritura, como forma de expresión emocional, pudo tener efectos terapéuticos a la hora de afrontar emociones negativas. Las cartas se transformaron en un espacio idóneo para la convivencia íntima y dibujaron, en palabras de Gurkin Altman:

Las coordenadas personales - temporales, espaciales, emocionales, intelectualespara decir a alguien en dónde estamos en un momento determinado y hasta dónde hemos viajado desde el último escrito. Los puntos de referencia de este mapa pertenecen tan solo al mundo compartido por quien escribe y quien recibe la carta: el diálogo epistolar es subrayado por los recuerdos comunes $\mathrm{y}$, a menudo, por las experiencias comunes que se producen entre la escritura y las cartas. ${ }^{35}$

En este sentido, creemos que una de las mayores virtudes de las cartas que a continuación presentaremos reside en reunir las letras del exilio anónimo y del que podríamos denominar de «segunda fila». Gente común, jóvenes estudiantes y profesionales que, por su compromiso con la política y el miedo producido por el auge de la violencia desde comienzos de la década de 1970, se vio obligada a salir al exterior para salvaguardar su vida del terrorismo de Estado. A través de estas palabras de ida y vuelta encontramos, por un lado, el testimonio de quienes protagonizaron este episodio de supervivencia y, por otro, la tabla de salvación que supusieron las cartas durante el exilio. Como afirma Laura Giussani, artífice de esta

34 Encuentro «Epistolarios del extremo. Campos, cárceles y exilios en el siglo XX». Organizado por Alicia Alted Vigil et al., Madrid, Universidad de Alcalá, Facultad de Filosofía y Letras, 11 y 12 de junio de 2018.

35 Rodríguez-López y Ventura Herranz, 2014, 119. 
colección y ella misma exiliada cuando contaba con dieciséis años, sobre su propio acervo: su «mayor interés es, justamente, ver la forma de encarar el mundo de una pibita, ex militante de la UES — Unión de Estudiantes Secundarios-, exiliada, que debía afrontar no solo las noticias de los amigos muertos o secuestrados, las tareas de solidaridad en el exterior sino también la vida cotidiana de ganar algo de plata para sobrevivir». ${ }^{36}$

\section{Fronteras difusas. Lo público y lo privado a través de la letra escrita}

Las cuatro emociones predominantes en los regímenes emocionales, en términos de Reddy, que sostuvieron y que sostienen los exilios y las migraciones forzadas fueron y son la tristeza, el miedo, la ira y la felicidad. Esta última emoción, de tipo positivo, solía aflorar al final de un día superado sin demasiadas dificultades ni sobresaltos o al recibir un sobre de papel con la letra de algún ser querido. Como señala Paula Schprejer, militante de la UES y exiliada en Israel en 1976, «las cartas eran como el pan». ${ }^{37}$ En el libro Los chicos del exilio. Argentina (1975-1984), el cual reconstruye las vivencias de quienes experimentaron el destierro durante su adolescencia, queda plasmada la importancia del rol desempeñado por las cartas, tanto para mantener el contacto con familiares, amistades y compañeros/as de militancia, y por ende la «comunidad emocional» a la que se adscribían, como para dejar constancia de su propia vida, de sus sentimientos y pensamientos. Según Beatriz Ruiz, coautora de Los chicos del exilio, cuya trayectoria de vida venimos reconstruyendo como integrante de la segunda generación de la expatriación republicana y de la inmigración española de posguerra en Argentina, y, además, militante de la UES y exiliada en Israel y en España entre 1977 y 1984:

Escribíamos mucho [...] teníamos una especie de ceremonia: los domingos a la tarde, todas las semanas, escribíamos cartas. Muchas cartas. Cartas a la familia, cartas a los amigos. A los que estaban en la Argentina y a los que estaban en Israel, en Inglaterra, y en otras partes. Teníamos amigos repartidos por todos lados. No había e-mail, y las cartas eran manuscritas [...] Cartas de gente que no tenía registro de que me había escrito, compañeros del colegio que no tenían nada que ver con la historia de la militancia política, amigos de la familia, alguna compañera de trabajo. ${ }^{38}$

36 Toso, 2017.

37 Guelar et al., 2002, 206.

38 Ibidem, 94. 
Daniel Korinfeld, compañero de Beatriz Ruiz, también militante de la UES y autor del libro Experiencias del exilio. Avatares subjetivos de jóvenes militantes argentinos durante la década del setenta ${ }^{39}$ reitera en sus palabras la presencia de las cartas en la diáspora como si de un protagonista más se tratara. Su testimonio, como adolescente en el exilio, da cuenta de algunos de los rituales que se crearon en torno a la correspondencia. En este caso, además de sumarse a la escritura dominical de su pareja, confiesa su obsesión por mirar el buzón del piso madrileño donde vivían: «A veces bajábamos más de una vez solamente para eso, y mirábamos fijamente la ranura o el plástico puesto a tal efecto, tratando de adivinar si se veían esas rayitas celestes entre intervalos blancos, los patrióticos bordes que anunciaban que esos papeles escritos por los nuestros habían llegado». ${ }^{40}$

Por supuesto, aquellas palabras de ida y vuelta que hicieron la vida cotidiana más llevadera, también fueron mensajeras de noticias funestas, de violencias y desapariciones, de detalles mundanos - alquileres, convivencias, trámites, burocracias, climas, paisajes, añoranzas gastronómicas- o de preocupaciones e inquietudes puntuales de cierto sector de la juventud contracultural que, tal vez, nos resulten inverosímiles en un contexto dictatorial, como son las del cultivo de hongos y marihuana, la vida en las comunidades hippies del sur de Argentina o Dinamarca, e incluso los eventos culturales del underground porteño. ${ }^{41}$ Las cartas se convirtieron en el soporte idóneo para mostrar — en la mayoría de los casos de manera inconsciente- la comunión que se produjo en buena parte de la juventud entre lo privado y lo público, lo personal y lo político, como consecuencia de «los mayos del sesenta y ocho». ${ }^{42}$

Como han señalado diferentes autoras, la militancia en la extrema izquierda de los años setenta constituyó una entrega total de los cuerpos a la revolución. ${ }^{43}$ El compromiso político imantó la vida social, cultural, amorosa y sexual. En palabras de Isabela Cosse, entablar una relación afectiva, comenzar a vivir en pareja y tener o no descendencia fueron decisiones con efectos políticos. Para este sector de la juventud vinculado con la nueva izquierda, la pareja y la familia que se formaba tenía que ser revolucionaria.

39 Korinfeld, 2008.

40 Guelar et al, 2002, 150.

41 Cartas de amigos/as dirigidas a Omar David Varela, Argentina-Suecia, 1978, 1979, 1980, BNA, Departamento de Archivos, Colección Cartas de la Dictadura, Sección Omar David Varela, Serie Correspondencia.

42 Frank, 2000

43 Andújar, 2009. Oberti, 2015. Moreno Seco, 2017. 
No bastaba con militar a tiempo completo, proletarizarse o, en el caso de quienes todavía cursaban estudios secundarios, trasladarse a institutos periféricos, había que confiar el cuerpo y los afectos a la revolución. ${ }^{44} \mathrm{La}$ politización de lo privado marcó a esta juventud revolucionaria y la pareja heterosexual fue concebida como la «célula básica» de afecto y acción en la concepción militante. La moral revolucionaria, además, estableció como principio la igualdad entre los sexos pero, como remarcó Marta Vasallo, militante de Montoneros y exiliada en España entre 1978 y 1983, «de la teoría a la práctica la brecha era importante». ${ }^{45}$

Luis Mattini, último Secretario General del PRT-ERP, exiliado en España y en Suecia, reconoce la fuerte presencia del machismo en su organización, incluso en él mismo. ${ }^{46}$ Sin embargo, y aquí la grandeza de la escritura privada, sus cartas halladas en el fondo de Diana Cruces, dan cuenta, por ejemplo, de un régimen emocional referente a la paternidad que difiere del de sus predecesores y entra en contradicción con la máxima revolucionaria de supeditar las emociones a la razón. Las letras escritas durante el exilio trasmiten el afecto y la ternura que algunos hombres sintieron por los hijos e hijas de sus parejas, fruto de relaciones anteriores. No olvidemos que en el universo de la nueva izquierda argentina se tomó como un precepto revolucionario asumir la paternidad de aquellos niños y niñas cuyos padres habían muerto o estaban presos. En este sentido, son muy elocuentes las cartas enviadas por el propio Luis Mattini a Diana Cruces, también militante del PRT-ERP, obligada a exiliarse en Perú y después refugiada en Francia junto a su hijo Guillermo, nacido en cautiverio $;{ }^{47}$ o por Ricardo Pato Zuker a Marta Maca Libenson, ambos con trayectoria militante en la UES y, posteriormente, vinculada a Montoneros, exiliados en Brasil y en España, concretamente en Madrid. Para mostrar solo un ejemplo, destacamos las palabras de Pato Zuker a Marta Libenson sobre Ana Victoria, nacida de una relación anterior con un compañero de militancia, muerto o suicidado - según las diferentes versiones- en 1976, cuando Marta se encontraba en su octavo mes de embarazo: «Toda la gente que vi y que te ha visto me cuenta que la gorda está muy bien y que aparte me nombra mucho, te imaginarás

44 Cosse, 2017.

45 Vasallo, 2009, 26.

46 Mattini, 2007

47 Véase, por ejemplo, la carta enviada por Luis Mattini a Diana Cruces, Madrid-París, 14 de diciembre de 1978, BNA, Departamento de Archivos, Colección Cartas de la Dictadura, Sección Diana Cruces, Serie Correspondencia. 
como se me cae la baba. La extraño muchísimo y casi todos los días miro su foto y la que estamos los tres juntos como forma de sentirme cerca de ustedes». ${ }^{48}$

Sin embargo, tampoco debemos de olvidar que, tal y como señala Elena Díaz para el caso del exilio republicano, la escritura del yo en cierto modo se convirtió en un medio - en el caso de las autobiografías, definido con mayor precisión - para, de manera consciente o inconsciente, reconstruir la identidad de género tras la quiebra del modelo normativo con el fin de la Guerra Civil y la imposición del exilio. ${ }^{49}$ En el caso de la expatriación de Argentina de los años setenta, si bien todavía está pendiente de estudio la evolución de las masculinidades, también observamos que tras la «derrota», en muchos casos, la represión, la violencia ejercida sobre sus cuerpos por parte de las fuerzas de seguridad, la cual solía atentar contra su propia «virilidad», y el destierro, se impone la necesidad de rehabilitar un modelo de masculinidad que también va a estar vinculado con valores como la conciencia paterna y el deseo de protección.

Aun así, pese a que las cartas analizadas dan cuenta de la participación afectuosa de algunos varones en los procesos de crianza, en lo que coinciden diversos testimonios de militantes revolucionarias, ${ }^{50}$ también se corrobora que las mujeres continuaron aglutinando las múltiples tareas referidas a los cuidados. De este modo, encontramos numerosas líneas en los epistolarios que remiten a la extenuación por las jornadas de trámites burocráticos, estudio, trabajo y maternidad, en el caso de algunas, siendo muy jóvenes. Pero, al mismo tiempo, reafirman la idea de un compromiso militante mantenido durante el exilio, al que se suman los retoños con plena naturalidad e incluso como acicate de la militancia. El fondo donado por la periodista Cristina Zuker, donde encontramos la correspondencia entre su hermano Ricardo y Marta Libenson, es una referencia clave en este sentido. En el caso de esta pareja, sería fundamental reconstruir su relación epistolar, ya que, tras un primer encuentro puntual en el exilio, concretamente en Montevideo y algunas coincidencias en São Paulo, fueron forjando su compromiso amoroso a través de la correspondencia, hasta que finalmente Marta se instaló en Madrid con su hija Ana Victoria, nacida en Brasil. La historia de ambos queda plasmada, en buena cuenta, en el libro El tren de

48 BNA, Departamento de Archivos, Colección Cartas de la Dictadura, Sección Cristina Zuker, Serie Correspondencia.

49 Díaz, 2019, 76.

50 Marta, 1996, 116. 
la victoria ${ }^{51}$ donde se analiza en detalle la historia de la familia Zuker y el retorno de su hermano a Argentina en el marco de la «Contraofensiva». ${ }^{52}$ En dicha operación perdió la vida esta joven pareja, dejando una niña huérfana que acabaría al cuidado, primero, de sus compañeros/as de militancia en una guardería en La Habana (La casita de caramelo) y, después, de sus abuelos maternos, quienes le ocultaron su verdadera identidad, finalmente descubierta poco antes de morir a causa de una enfermedad letal durante su adolescencia.

Pero más allá de la tragedia de esta historia, lo que nos interesa resaltar en este punto es que los intercambios epistolares entre esta pareja, fundamentalmente las cartas escritas por Marta Libenson, muestran una imagen muy alejada de la chica locamente enamorada, incluso algo desequilibrada, que podemos extraer de los relatos elaborados por Cristina Zuker. En sus cartas, encontramos a una mujer joven con un firme compromiso político que, como tantas otras militantes, a pesar de haber concebido y parido a criaturas en condiciones de extremo riesgo, después de haberse convertido en madre, se reafirmó en sus convicciones y preceptos revolucionarios. Al menos en cuanto a la maternidad se refiere, concibió esta experiencia como un estímulo para continuar en la lucha por una sociedad más justa y libre de la doble moral burguesa. Así, Marta Libenson o Maca, a punto de regresar a Argentina de manera clandestina, reforzaba su postura política en la figura de su hija, y se lo transmitía en estos términos a su pareja: «Cómo sabés mi limitación principal entre una serie de cosas es Ana Victoria, pero lo que me he dado cuenta es que justamente por ella, por como se gestó y para qué futuro la criamos, no puede ser una limitación para ninguno de nosotros. Al contrario. Tiene que ser una guía ante cualquier decisión».53 Todas sus cartas, más allá de los problemas ocasionados por la vida cotidiana en el exilio, por el dolor de las pérdidas, por la crianza en solitario durante los primeros meses, rezuman vitalidad y compromiso. Nada más lejos de la afirmación de la que fuera su cuñada en una entrevista concedida a Página 12 en 2003, cuyo titular rezaba «es

51 Zuker, 2003.

52 Así se denominó la estrategia diseñada por la cúpula dirigente de Montoneros para que militantes exiliados/as en el exterior ingresaran clandestinamente a Argentina, con el objetivo de retomar la lucha armada y/o llevar a cabo acciones de desestabilización contra la dictadura militar en 1978 y en 1980.

53 Carta de Marta Libenson a Ricardo Zuker, Madrid-Buenos Aires, sin fecha, BNA, Departamento de Archivos, Colección Cartas de la Dictadura, Sección Cristina Zuker, Serie Correspondencia. 
como si hubiesen vuelto para no salvarse», ${ }^{54}$ ya que - como conocemos a través de sus epístolas - entre los planes inminentes de la joven pareja figuraba la descendencia.

Esta comunión entre lo público y lo privado, lo político y lo personal, también está presente en los fondos donados por las hermanas Giussani. En estos encontramos, por un lado, las cartas de sus padres, donde se habla de los problemas de la vida cotidiana en diferentes puntos del exilio o de las amistades que han quedado en Argentina, sin olvidar en una sola de las epístolas el precepto de continuar escribiendo como forma de mantener unida a la familia, disgregada en la geografía del exilio. Y, por otro, las cartas escritas por amigas, en su mayoría militantes adolescentes de organizaciones estudiantiles, en las que se transmiten informaciones referidas a compañeros y compañeras secuestrados/as y desaparecidos/as, ${ }^{55}$ las cuales fueron fundamentales para dotar de contenido a los colectivos de denuncia de la violación de los derechos humanos en el exterior. Pero, por lo general, lo que abundan son datos, reflexiones o sentimientos referidos a la vida cotidiana en el exterior, combinados con recuerdos y añoranzas del pasado inmediato. Un buen ejemplo de ello es esta carta enviada por Hebe - de quien desconocemos sus apellidos—, exiliada en París, a su amiga Virginia Giussani, exiliada en Roma, con fecha de 19 de noviembre de 1978. En ella, tras un detenido repaso sobre algunas decisiones de la cúpula dirigente de Montoneros, las sospechas generadas por las palabras y acciones de sus miembros, la ira y la tristeza que estas le habían producido como militante, le cuenta a su amiga que ha decido dar un paso al costado y separarse de la Organización. A continuación, cortando ese hilo tan delgado que separa lo público de lo privado, lo político de lo personal, prosigue con un texto que no tiene desperdicio:

En fin, cada cual con su conciencia. Yo con la mía. Y a seguir adelante. Hubo una semana en la que la pasé que bueno, bueno. Hasta me pregunto porque [sic] mierda estoy entonces en el exilio, o porque [sic] Polito desapareció, o porque..., que se yo [sic], tengo la cabeza llena de porqués. En cuanto a otras cosas, todo va bien, el baby en plena salud, patea bastante y yo gorda como un elefante, ya que faltan nada más

54 Friera, 2003.

55 Entre ellas, destacamos la carta enviada por una compañera a Laura Giussani, en la que elabora de memoria un listado con los nombres de amistades en común, chicos y chicas de entre 15 y 18 años, secuestradas y desaparecidas en los últimos meses, diciembre de 1976, BNA, Departamento de Archivos, Colección Cartas de la Dictadura, Sección Laura Giussani, Serie Correspondencia. 
que 25 días para que nazca. Hoy terminé un trabajo que me tenía todo el día como loca, y era pasar a máquina un libro por el cual me pagan $[\ldots]^{56}$

Después, informa a su amiga de que se ha cambiado de universidad, está estudiando teatro, hace deporte y, junto a su pareja, se está mudando a una casa en obras donde recibirán la visita de su madre en quince días: «La verdad es que no veo la hora de que se pase todo (mudanza y parto) a pesar de que yo no me puedo quejar del embarazo que tuve ya que lo pasé re-bien [...] Pero como te imaginarás todo se condiciona muchísimo a la llegada del nuevo miembro de la familia (Para lo cual no tengo mucha experiencia)». Finalmente se despide hablando de algunos productos gastronómicos que ha recibido de su tierra y acotando: «Bueno, te dejo aquí. Porque estoy HARTA de escribir [...]. Aunque esta carta es media idiota, tratá de no darte cuenta y contéstame igual».57

Lamentablemente, carecemos de otras epístolas que nos ayuden a recabar más información sobre el futuro de esta joven exiliada. Y es aquí donde, desde nuestro punto de vista, reside una de las principales limitaciones con la que nos encontramos a la hora de abordar el estudio sistemático de las diferentes secciones que componen este fondo archivístico: la interrupción de secuencias cronológicas. En pocos casos contamos con las cartas enviadas y la contestación recibida, lo que dificulta la reconstrucción, por ejemplo, de trayectorias vitales y emocionales en periodos cortos de tiempo. A este factor se une la escasez de series referidas en exclusiva al exilio y, en particular, al que hemos denominado de segunda fila. En este sentido, podríamos señalar la contradicción de una misma fuente que visibiliza a un sector concreto de la expatriación, pero que no nos permite por si sola avanzar en su conocimiento.

Del mismo modo, debemos hacer referencia a la sombra de la censura. En este caso, al menos en los documentos analizados, no encontramos marcas visibles, ni apreciamos a priori un lenguaje críptico o en clave. Las cartas censuradas por los propios militares son más evidentes en las series relacionadas con la cárcel, en particular las producidas desde la cárcel de Devoto, donde se encontraban las presas políticas «legalizadas». Como señala Horacio González, en esos casos, el sello significaba que el censor las

56 Carta de Hebe a Virginia Giussani, París-Roma, 19 de noviembre de 1978, BNA, Departamento de Archivos, Colección Cartas de la Dictadura, Sección Virginia Giussani, Serie Correspondencia.

57 Idem. 
había leído y las había dejado pasar, según sus palabras «por esas paradojas del lenguaje militar, "censurada" quiere decir "pasó sin censura"». ${ }^{58}$

En el caso de las cartas analizadas, tenemos la impresión de que sus artífices fueron cuidadosas/os a la hora de ofrecer datos que pudieran exponer a un peligro todavía mayor a sus familias y amistades, tanto quienes estaban en el interior como en el exterior, donde desde la implantación de la dictadura se supo de las labores de espionaje llevadas a cabo por el ejército, el cuerpo diplomático y los distintos gobiernos militares y civiles. Pero ello no impidió que las mismas se convirtieran en un nexo articulador de redes y en un soporte canalizador de emociones y afectos. En definitiva, las cartas desde y hacia el exilio se convirtieron en una muestra más de ese compromiso militante dispuesto a transgredir las normas impuestas desde arriba, en este caso el silencio del destierro.

\section{A modo de conclusiones}

Con este artículo, fruto de una investigación en curso, hemos creído oportuno mostrar las potencialidades hermenéuticas de la aplicación tanto de la perspectiva de género en el análisis del exilio como de una fuente histórica todavía no incorporada con la importancia debida al estudio del exilio rioplatense. En particular, hemos querido abordar algunos de los aspectos que hacen referencia al compromiso militante y a la afectividad, campo para el que la historia de las emociones nos brinda unas herramientas conceptuales adecuadas, para revelar esa connivencia entre lo público y lo privado y su manifestación a través de la escritura personal. Asumimos las limitaciones del presente trabajo, ya que por su propia concepción es imposible canalizar en él el estudio en profundidad que se está llevando a cabo sobre los epistolarios. A través de los fragmentos seleccionados, de los temas que en cada uno de los fondos particulares hemos ido abordando, con el objetivo de establecer un diálogo entre los mismo, nos resulta imposible dar cuenta de la variedad de tópicos que podía contener una carta, ya fuera escrita por una mujer o por un hombre. En este sentido, coincidimos con Mónica Moreno y Alicia Mira, quienes, tras analizar las memorias de hombres y mujeres durante la Guerra Civil y el exilio, matizaban la visión estereotipada entre unas memorias masculinas, centradas en lo público,

58 González, 2015, 7. 
y unas memorias femeninas, centradas en lo privado. ${ }^{59}$ En su estudio defienden que, aunque en estas memorias perviven los estereotipos de género, el compromiso político, entendido dentro de un contexto exiliar, se difumina una separación rígida entre esferas de actuación masculinas — supuestamente públicas - y las femeninas, circunscritas al hogar y la maternidad. Otros factores como la edad, el grado de vinculación política o el peso de valores éticos, vinculados por lo general a la izquierda, contribuirían a matizar estos comportamientos.

En los epistolarios analizados existe esta coincidencia, y en las cartas, independientemente del género de su autoría, encontramos referencias directas a temas familiares, afectivos, de crianza, políticos, de añoranza, culturales, logísticos, etcétera. No obstante, es evidente que en el epistolario de una madre joven que está sola en el exilio con su hija, los aspectos que hacen referencia a los cuidados y a la vida cotidiana ocuparan un lugar destacado. Lo que no quiere decir que la militancia, el compromiso político que, sumado al terrorismo de Estado, fue lo que las obligó a exiliarse para salvar su vida, o que el amor hacia su pareja desaparezca de su pensamiento $y$, por tanto, de la escritura privada.

En definitiva, los epistolarios inéditos, como ya han demostrado las colegas que abordan el exilio republicano español, son un instrumento eficaz para seguir incorporando a la gente común —y en particular a los sujetos subalternos- en los movimientos migratorios de carácter forzado. Sin embargo, la interrupción de secuencias cronológicas y la escasez de series referidas en exclusiva al exilio son dos de sus principales desventajas o inconvenientes. $\mathrm{Al}$ menos esto se desprende del fondo «Cartas de la Dictadura» albergado en la Biblioteca Nacional de Argentina, en el cual hemos basado nuestras pesquisas. Aún así, valoramos positivamente el hecho de contar con testimonios privilegiados, producidos en un contexto preciso, sin pasar por el tamiz de la memoria, de modo que, contrastados con otras fuentes, nos pueden ayudar a conocer las subjetividades exiliadas, así como a plantear nuevas vías de análisis y discutir o matizar ciertos axiomas ya establecidos. Como ha señalado Luis Roniger para los exilios latinoamericanos y Núñez-Seixas para los ibéricos, todavía es necesario mover el análisis de los exilios iberoamericanos hacia los estudios comparativos y cruzados, la larga duración y el ámbito transnacional. ${ }^{60}$ Para ello, será preciso, entre otros, ampliar las fuentes históricas, las temáticas abordadas y

59 Moreno y Mira, 2009, 251.

60 Roniger, 2011. Núñez-Seixas, 2020. 
las perspectivas desde las cuales afrontamos nuestras investigaciones. En este sentido, el estadio alcanzado por los análisis sobre el exilio republicano español y, en concreto, sobre las mujeres expatriadas, nos puede servir de guía para continuar arrojando luz sobre el exilio de las militantes argentinas de los años setenta. De ahí partimos y en ello continuamos trabajando. Son muchas las preguntas que todavía nos acechan y arduo el camino por recorrer para que la pregunta de Montserrat Roig no se haga eterna.

Recibido, 27 de noviembre de 2019

Segunda versión, 17 de marzo de 2020

Aceptado, 23 de marzo de 2020

\section{Referencias bibliográficas}

Adámez Castro, Guadalupe, Gritos de papel. Las cartas de súplica del exilio español (1936-1945), Granada, Comares, 2017.

Álvarez, Victoria, «Un tiempo suspendido. Vida cotidiana y devenir feminista de mujeres argentinas exiliadas durante la última dictadura militar (19761983)», Arenal, 26, Granada, 2019, 427-447.

Amado, Ana, «Memoria, parentesco y política», Debate Feminista, 14, México, 2003, 50-75.

Andújar, Andrea et al. (comps.), De minifaldas, militancias y revoluciones. Exploraciones sobre los 70 en la Argentina, Buenos Aires, Luxemburg, 2009.

Antonio, Débora d', "Represión y resistencia en las cárceles de la última dictadura militar argentina", La revista del CCC, 2, Buenos Aires, 2008. Disponible en: https://www.centrocultural.coop/revista/2/represion-y-resistencia-en-lascarceles-de-la-ultima-dictadura-militar-argentina [Consultado: 12/09/2018].

Antonio, Débora d', La prisión en los años 70. Historia, género y política, Buenos Aires, Biblos, 2016.

Antonio, Débora d', «La escritura femenina en tiempos de encierro como forma de intervención política (Argentina, Villa Devoto, 1976-1983)», Historia del Presente, 33, Madrid, 2019, 41-56.

Bayer, Osvaldo, «Las cartas del exilio», Página 12, Buenos Aires, 28 de enero de 2007. Disponible en: https://www.pagina12.com.ar/diario/suplementos/ radar/9-3553-2007-01-29.html [Consultado: 16/07/2019].

Beguán, Viviana; Kozameh, Alicia y Echarte, Silvia, Nosotras las presas políticas, Buenos Aires, Nuestra América, 2006.

Burgos Fonseca, Isabel, «Feminismos y exilios. Genealogías del feminismo latinoamericano», en Lastra, Soledad (comp.), Exilios. Un campo de estudios en expansión, Buenos Aires, Consejo Latinoamericano de Ciencias Sociales, 2018, 223-234. 
Chiaramonte, José Carlos y Klein, Herbert, El exilio de Perón. Los papeles del Archivo Hoover, Buenos Aires, Sudamericana, 2017.

Cosse, Isabella, «"Infidelidades”: Moral, revolución y sexualidad en las organizaciones de la izquierda armada en la Argentina de los años 70», Prácticas de oficio, 19, Buenos Aires, 2017. Disponible en: https://static.ides.org.ar/ archivo/www/2012/04/1.-COSSE.pdf [Consultado: 16/07/2018].

Davidovich, Karin, «Voces femeninas. Género, memoria y exilio en las narrativas testimoniales de mujeres argentinas», Kamtchatka, 8, Valencia, 2016, 11-22.

Díaz Silva, Elena, Héroes, indeseables y vencidos. La quiebra y la reconstrucción del modelo de masculinidad en el exilio mexicano, Granada, Comares, 2019.

Franco, Marina, Un enemigo para la nación. Orden interno, violencia y «subversión», 1973-1976, Buenos Aires, Fondo de Cultura Económica, 2012.

Frank, Robert, «Introduction», en Dreyfus-Armand, Geneviève et al. (dirs.), Les Années 68. Le temps de la contestation, Paris, Complexe, 2000, 13-21.

Friera, Silvina, «Es como si hubiesen vuelto para no salvarse», Página 12, Buenos Aires, 16 de diciembre de 2003. Disponible en: https://www.pagina12.com. ar/diario/cultura/7-29338-2003-12-16.html [Consultado: 16/07/2019].

González de Oleaga, Marisa et al., Transterradas. El exilio infantil y juvenil como lugar de memoria, Buenos Aires, Trenenmovimiento, 2019.

González, Horacio, Cartas de la dictadura, Buenos Aires, Biblioteca Nacional, 2015.

Grinberg, León y Grinberg, Rebeca, Psicoanálisis de la migración y del exilio, Madrid, Alianza, 1984.

Guelar, Diana et al., Los chicos del exilio, Buenos Aires, El País del Nomeolvides, 2002.

Hoyos, Jorge de, «La historiografía sobre refugiados y exiliados políticos en el siglo XX: el caso del exilio republicano español de 1939», Ayer, 106, Madrid, 2017, 293-305.

Jensen, Silvina, «Reflexiones sobre el lugar de las mujeres en la memoria del exilio. Las exiliadas argentinas en Cataluña», en Guardia, Sara B. (ed.), $L a$ escritura de la Historia de las mujeres en América Latina. El retorno de las diosas, Lima, Centro de Estudios de la Mujer en la Historia de América Latina, 2005, 523-547.

Jensen, Silvina, «Exilios. Desafíos y pontencialidades de la agenda del nuevo milenio», en Lastra, Soledad (comp.), Exilios. Un campo de estudios en expansión, Buenos Aires, Consejo Latinoamericano de Ciencias Sociales, 2018, 237-250.

Jensen, Silvina y Moreno Montero, María, «La escritura epistolar como registro de la experiencia de encierro y represión en las cárceles argentinas (19741983)», Historia Actual Online, 31, Cádiz, 2013, 143-157.

Korinfeld, Daniel, Experiencias del exilio. Avatares subjetivos de jóvenes militantes argentinos durante la década del setenta, Buenos Aires, Del Estante, 2008. 


\section{BÁRBARA ORTUÑO MARTÍNEZ}

Lewin, Miriam y Wornat, Olga, Putas y guerrilleras, Buenos Aires, Planeta, 2013. Manzano, Valeria, La era de la juventud en Argentina. Cultura, política y sexualidad desde Perón hasta Videla, Buenos Aires, Fondo de Cultura Económica, 2017.

Marta, Diana, Mujeres guerrilleras. La militancia de los setenta en el testimonio de sus protagonistas, Buenos Aires, Planeta, 1996.

Mattini, Luis, Los Perros 2. Memorias de la rebeldía femenina en los 70', Buenos Aires, Peña Lillo/Ediciones Continente, 2007.

Mira, Guillermo, «¿Sobrevivir o vivir en Madrid? Exiliados argentinos del 76», en Espina Barrio, Ángel B. (dir.), Antropología en Castilla y León e Iberoamérica, Salamanca, Universidad de Salamanca/Instituto de Investigaciones Antropológicas de Castilla y León, 2003, 187-198.

Moreno Seco, Mónica, «Las exiliadas, de acompañantes a protagonistas», Ayer. Revista de Historia Contemporánea, 81, Madrid, 2011, 265-281.

Moreno Seco, Mónica, «Sexo, Marx y nova cançó. Género, política y vida privada en la juventud comunista de los años setenta», Historia Contemporánea, 54, Bilbao, 2017, 47-84.

Moreno Seco, Mónica y Mira Abad, Alicia, «Entre el compromiso y la privacidad. Memorias de guerra y exilio de mujeres y hombres», Espacio, tiempo y forma. Serie V, Historia Contemporánea, 21, Madrid, 2009, 249-266.

Moreno Seco, Mónica y Ortuño Martínez, Bárbara, «Exiliadas españolas en Francia y Argentina: identidades transnacionales y transferencias culturales», Storia delle Donne, 9, Florencia, 2013, 161-196.

Núñez Seixas, Xosé Manoel, «Sobre diásporas, exilios e identidades en el siglo XX», en García Sebastiani, Marcela y Núñez Seixas, Xosé Manoel (eds.), Hacer patria lejos de casa. Nacionalismo español, migración y exilio en Europa y América (1870-2010), Zaragoza, Prensas de la Universidad de Zaragoza, 2020, 15-39.

Oberti, Alejandra, Las revolucionarias. Militancia, vida cotidiana y afectividad en los setenta, Buenos Aires, Edhasa, 2015.

Olmo Pintado, Margarita del, La construcción cultural de la identidad: emigrantes argentinos en España, Madrid, Editorial de la Universidad Complutense de Madrid, 1989.

Olmo Pintado, Margarita del, La utopía en el exilio, Madrid, Editorial CSIC, 2002.

Ortuño Martínez, Bárbara, «Jóvenes “expatriadas”. Un acercamiento al compromiso político de la segunda generación del exilio republicano en Argentina durante los años sesenta y setenta», Ayer. Revista de Historia Contemporánea, 100, Madrid, 2015, 23-147.

Ortuño Martínez, Bárbara, Hacia el hondo bajo fondo... Inmigrantes y exiliados en Buenos Aires tras la Guerra Civil española, Madrid, Biblioteca Nueva, 2018.

Ortuño Martínez, Bárbara, «Las violencias del exilio. Argentinas expatriadas en la España de los setenta», Historia del Presente, 33, Madrid, 2019, 25-40. 
Ortuño Martínez, Bárbara y Moreno Seco, Mónica, «Militantes entre el ser y el deber ser. Compromiso, género y familia en la juventud revolucionaria de los años setenta», Arbor, Madrid [en prensa].

Pozzi, Pablo, «Por las sendas argentinas...». El PRT-ERP. La Guerrilla marxista, Buenos Aires, Editorial Universitaria de Buenos Aires, 2001.

Rey, Eduardo y Coraza, Enrique, «Retornos forzosos del Cono Sur. En torno al exilio de los descendientes de españoles», en Liñares, Amancio (coord.), Hijos y nietos de la emigración española. Las generaciones del retorno, Vigo, Grupo España Exterior, 2009, 125-141.

Rodríguez López, Sofía, "“Todo sobre mi madre”. Un relato generacional de la vida y exilios de Carmen Tortosa», en Ramos, María Dolores et al. (coords.), Mujeres iberoamericanas y derechos humanos. Experiencias feministas, acción política y exilios, Sevilla, Athenaica, 2016, 348-383.

Rodríguez-López, Carolina y Ventura Herranz, Daniel, «De exilios y emociones», Cuadernos de Historia Contemporánea, 36, Madrid, 2014, 113-138.

Roniger, Luis, «Destierro y exilio en América Latina: Un campo de estudio transnacional e histórico en expansión», Pacarina del Sur, 1, México, 2011, Disponible en: http://www.pacarinadelsur.com/home/abordajes-y-contiendas/ 318-destierro-y-exilio-en-america-latina-un-campo-de-estudio-transnacionale-historico-en-expansion [Consultado: 12/02/2019].

Saidón, Gabriela, Yo me hice feminista en el exilio. Las historias de Dora Barranco, Susana Gamba, Susana Sanz y Tununa Mercado, Buenos Aires, IndieLibros, 2019.

Sierra Blas, Verónica, Cartas presas. La correspondencia carcelaria en la Guerra Civil y el franquismo, Madrid, Marcial Pons, 2016.

Simón, Paula, «Exilios cruzados: representaciones, identidades y memorias en los exilios europeos y latinoamericanos del siglo XX y XXI», Kamchatka, 8, Valencia, 2016, 5-10.

Toso, Carina, «Cartas de la dictadura: La historia escrita a mano», Enredando. Comunicación Popular, Argentina, 13 de febrero de 2017. Disponible en: http:// www.enredando.org.ar/2017/02/13/cartas-de-la-dictadura-la-historia-escritaa-mano/ [Consultado: 16/07/2019].

Vasallo, Marta, «Militancia y transgresión», en Andújar, Andrea et al. (comps.), De minifaldas, militancias y revoluciones. Exploraciones sobre los 70 en la Argentina, Buenos Aires, Luxemburg, 2009, 19-32.

Vásquez, Ana y Araujo, Ana María, La maldición de Ulises. Repercusiones psicológicas del exilio, Santiago de Chile, Sudamericana, 1990.

Yankelevich, Pablo, «Los exilios en el pasado reciente sudamericano», Migraciones y Exilios, 16, Madrid, 2016, 11-31.

Zuker, Cristina, El tren de la victoria. Una saga familiar, Buenos Aires, Sudamericana, 2003. 